\title{
Mucilaginibacter gossypii sp. nov. and Mucilaginibacter gossypiicola sp. nov., plant-growth-promoting bacteria isolated from cotton rhizosphere soils
}

Correspondence Munusamy Madhaiyan mmadhaiyan@hotmail.com

\author{
Munusamy Madhaiyan, ${ }^{1}$ Selvaraj Poonguzhali, ${ }^{1}$ Jung-Sook Lee, ${ }^{2}$ \\ Murugaiyan Senthilkumar, ${ }^{3}$ Keun Chul Lee ${ }^{2}$ and Subbiah Sundaram ${ }^{1}$ \\ ${ }^{1}$ Department of Agricultural Microbiology, Tamilnadu Agricultural University, Coimbatore 641003 , \\ Tamilnadu, India \\ ${ }^{2}$ Korean Collection for Type Cultures (KCTC), Biological Resource Center (BRC), \\ Korea Research Institute of Bioscience and Biotechnology (KRIBB), 111 Gwahangno, Yusong-gu, \\ Daejeon 305-806, Republic of Korea \\ ${ }^{3}$ Department of Agricultural Microbiology, Horticultural College and Research Institute, \\ Tamilnadu Agricultural University, Periyakulam 625 604, Tamilnadu, India
}

Beneficial plant-microbe interactions can result in the promotion of plant health and development and play a significant role in low-input sustainable agriculture applications. Several bacterial species are known to exert beneficial effects on plant growth (Vessey, 2003; Egamberdieva et al., 2008). The plant-growth-promoting effects of beneficial bacteria may be through direct or indirect mechanisms that include production of phytohormones or enzymes that

Abbreviations: ACC, 1-aminocyclopropane-1-carboxylate; EPS, extracellular polysaccharide.

The GenBank/EMBL/DDBJ accession numbers for the 16S rRNA sequences of strains $\mathrm{Gh}-67^{\top}$ and $\mathrm{Gh}-48^{\mathrm{T}}$ are EU672804 and EU672805.

Scanning electron micrographs of cells of strains Gh- $67^{\top}$ and $G$ h- $48^{\top}$ are available as supplementary material with the online version of this paper. promote plant growth, increased nutrient uptake and protection from deleterious phytopathogens (Glick et al., 1999; Whipps, 2001). Members of the phylum Bacteroidetes are widely distributed in aquatic and terrestrial habitats and have a key role in degrading various biopolymers (Floyd et al., 2005). The genus Mucilaginibacter Pankratov et al. 2007, a member of the family Sphingobacteriaceae Steyn et al. 1998, was proposed to group Gram-reaction-negative, nonspore-forming, non-motile rods that produced large amounts of extracellular polymeric substances (Pankratov et al., 2007). At the time of writing, the genus Mucilaginibacter includes seven species with validly published names, Mucilaginibacter paludis (the type species), $M$. gracilis, M. kameinonensis, $M$. daejeonensis, M. ximonensis, M. oryzae and $M$. rigui, which were isolated from an acidic sphagnum peat bog, dried rice straw, wetland fresh water and soil samples (Pankratov et al., 2007; Urai et al., 2008; An 
et al., 2009; Luo et al., 2009; Jeon et al., 2009; Baik et al., 2010). In this paper, we describe two Mucilaginibacter strains, Gh- $67^{\mathrm{T}}$ and Gh- $48^{\mathrm{T}}$, that are extracellular polysaccharide (EPS)-producing, plant-growth-promoting bacteria isolated from rhizosphere soil of cotton. Based on phenotypic, phylogenetic and genotypic characteristics, we suggest that strains Gh- $67^{\mathrm{T}}$ and Gh- $48^{\mathrm{T}}$ represent two novel species of the genus.

Samples of rhizosphere soil of cotton (Gossypium hirsutum L. 'MCU-12') were collected from an experimental field of the Cotton Breeding Station, Tamilnadu Agricultural University (TNAU), Coimbatore, Tamilnadu, India. Two highly distinctive types of either cream- or pink-coloured, raised, semi-transparent and slimy colonies developed on selective ammonium mineral salts (AMS) medium (Whittenbury et al., 1970) supplemented with filtersterilized cycloheximide $\left(10 \mu \mathrm{g} \mathrm{ml} \mathrm{m}^{-1}\right)$ and $0.5 \%(\mathrm{v} / \mathrm{v})$ methanol or R2A agar (Difco) with $1 \%(\mathrm{v} / \mathrm{v})$ methanol, inoculated with the terminal dilution of a soil suspension.

Morphological properties were studied and nutritional and phenotypic characterization was carried out according to previously described protocols (Gerhardt et al., 1994; Green \& Bousfield, 1982). Gram staining was performed by using a Gram staining kit (Difco) and bacterial suspensions were examined by phase-contrast microscopy for cell morphology and motility. Growth was tested on nutrient (NA; Difco), tryptic soy agar (TSA) (3 g tryptic soy broth $\mathrm{1}^{-1}$; Difco), R2A (Difco) and MacConkey agars. The $\mathrm{pH}$ range for growth was determined on AMS agar. Growth temperature $\left(4,10,20,25,30,37\right.$ and $\left.45^{\circ} \mathrm{C}\right)$ and $\mathrm{NaCl}$ tolerance $[0,1,2,3,4,5$ and $10 \%(\mathrm{w} / \mathrm{v})]$ were tested on AMS medium. Catalase activity was determined by assessing bubble production in $3 \%(\mathrm{v} / \mathrm{v}) \mathrm{H}_{2} \mathrm{O}_{2}$, and oxidase activity was determined using $1 \%(\mathrm{w} / \mathrm{v})$ tetramethyl-p-phenylenediamine using Difco BBL catalase and oxidase reagent droppers according to the manufacturer's instructions (Difco, Becton Dickinson). Tests for hydrolysis of starch, casein, CM-cellulose, gelatin, aesculin and pectin were performed and evaluated after 5 days (Atlas, 1993; Kouker \& Jaeger, 1987; Ten et al., 2004). Lipolytic and proteolytic activities were investigated on plates containing tributyrin agar base and $1 \%$ glycerol tributyrate (Sigma) and $10 \%$ TSA with $1.5 \%$ skimmed milk powder, respectively. The plates were incubated for 3-5 days and examined for the presence of clearance zones around growing colonies. Nutritional features were determined using Biolog GN2 Microplates (Madhaiyan et al., 2007a); carbon-source utilization tests other than those included in the Biolog plate were performed using a standard protocol (Green \& Bousfield, 1982). Urease activity was tested using urea broth according to the manufacturer's instructions (Difco). Scanning electron microscope observations were performed as described by Bozzola \& Russell (1998) using a Hitachi S-2500C instrument with GEMINI column (Hitachi Co.) equipped with a field-emission electron source. Quinones were extracted and analysed according to Kroppenstedt (1982). Flexirubin-like pigments were observed by flooding the plates with $20 \%(\mathrm{w} / \mathrm{v})$ potassium hydroxide (Fautz \& Reichenbach, 1980). Pigments were extracted from cultures grown in R2A liquid medium for 5 days using methanol and the resultant supernatant was scanned for absorbance at wavelengths of 190-1100 nm at room temperature on a UV-1601 spectrophotometer (Shimadzu). The antibiotic resistance patterns of the strains were determined and the detection and quantification of EPS were carried out as described previously (Chanprame et al., 1996; Urai et al., 2008).

Both strains were aerobic and Gram-negative and produced large amounts of an EPS. The cells were nonendospore-forming, non-motile, irregular short rods, 0.18 $0.29 \mu \mathrm{m}$ wide and $0.51-1.25 \mu \mathrm{m}$ long, in chains when cultured on AMS agar plates at $25^{\circ} \mathrm{C}$ for 2 days (Supplementary Fig. S1, available in IJSEM Online). Growth was observed on AMS or R2A medium supplemented with methanol, while no growth was observed on TSA or MacConkey agar. The strains showed good growth in the presence of $0.5 \%(\mathrm{w} / \mathrm{v}) \mathrm{NaCl}$ in AMS, but little or no growth occurred in the presence of $1 \%(\mathrm{w} / \mathrm{v}) \mathrm{NaCl}$ or higher. The nutritional and physiological characteristics of strains $\mathrm{Gh}-67^{\mathrm{T}}$ and $\mathrm{Gh}-48^{\mathrm{T}}$ are detailed in the species descriptions and differentiating characteristics from their closest relatives are given in Table 1.

A quantitative assay for the estimation of indole-3-acetic acid and plate assays for detecting the presence of siderophore production, 1-aminocyclopropane-1-carboxylate (ACC) deaminase activity and sulfur oxidation were carried out as described previously (Poonguzhali et al., 2006). A gnotobiotic assay using growth pouches was performed to measure root elongation induced by ACC deaminase. Tomato and canola seeds were used for this assay, since they are better representative of ethylenesensitive plants (Glick et al., 1994; Li et al., 2000; Penrose \& Glick, 2003; Ghosh et al., 2003; Madhaiyan et al., 2006, 2007b). The minimal inhibitory concentrations of heavy metals for the strains were determined as described by Madhaiyan et al. (2007b). Strains Gh- $67^{\mathrm{T}}$ and Gh- $48^{\mathrm{T}}$ were able to tolerate up to $1 \mathrm{mM} \mathrm{NiCl} / \mathrm{CdCl}_{2}$ and showed growth on plates, and no growth was observed above this concentration. From gnotobiotic growth pouch assays, the root length of tomato (23.3 and $32.9 \%$ increase over controls, respectively) and canola (10.4 and 17.2\%) seedlings treated with Mucilaginibacter strains Gh- $67^{\mathrm{T}}$ and $\mathrm{Gh}-48^{\mathrm{T}}$ was comparatively greater when compared with uninoculated controls. Both strains possessed ACC deaminase activity and oxidized sulfur when examined through plate assays but were negative in the siderophore assay. Strains Gh- $67^{\mathrm{T}}$ and Gh- $48^{\mathrm{T}}$ produced ACC deaminase activity of 5.32 and $12.32 \mathrm{nmol} \alpha$-ketobutyrate $(\mathrm{mg}$ protein $)^{-1} h^{-1}$. Both strains showed the presence of the acdS gene that encodes ACC deaminase activity when DNA extracts was analysed through PCR using the primer pair F1936/F1939 (Blaha et al., 2006); a product of the expected size (558 bp) was detected, similar to the acdS genes of Methylobacterium species (Madhaiyan et al., 2009). 
Table 1. Physiological characteristics that allow differentiation among members of the genus Mucilaginibacter

Strains: 1, Mucilaginibacter gossypii sp. nov. Gh- $67^{\mathrm{T}}$; 2, Mucilaginibacter gossypiicola sp. nov. Gh- $48^{\mathrm{T}}$; 3, M. kameinonensis KCTC $22227^{\mathrm{T}}$; 4 , M. gracilis KACC $13451^{\mathrm{T}}$; 5 , M. paludis KACC $13450^{\mathrm{T}} ; 6$, M. daejeonensis Jip $10^{\mathrm{T}} ; 7$, M. ximonensis XM- $003^{\mathrm{T}} ; 8$, M. oryzae $\mathrm{B} 9^{\mathrm{T}}$. Data in columns $1-5$ were obtained in this study and those in columns 6-8 were taken from An et al. (2009); Luo et al. (2009) and Jeon et al. (2009). +, Growth; -, no growth; w, weak growth; ND, no data available/not determined. All strains are positive for catalase production and assimilation of cellobiose, Dgalactose, D-fructose, maltose, $\mathrm{N}$-acetyl-D-glucosamine and lactose. All strains are negative for growth at $45{ }^{\circ} \mathrm{C}$, utilization of acetate and indole production.

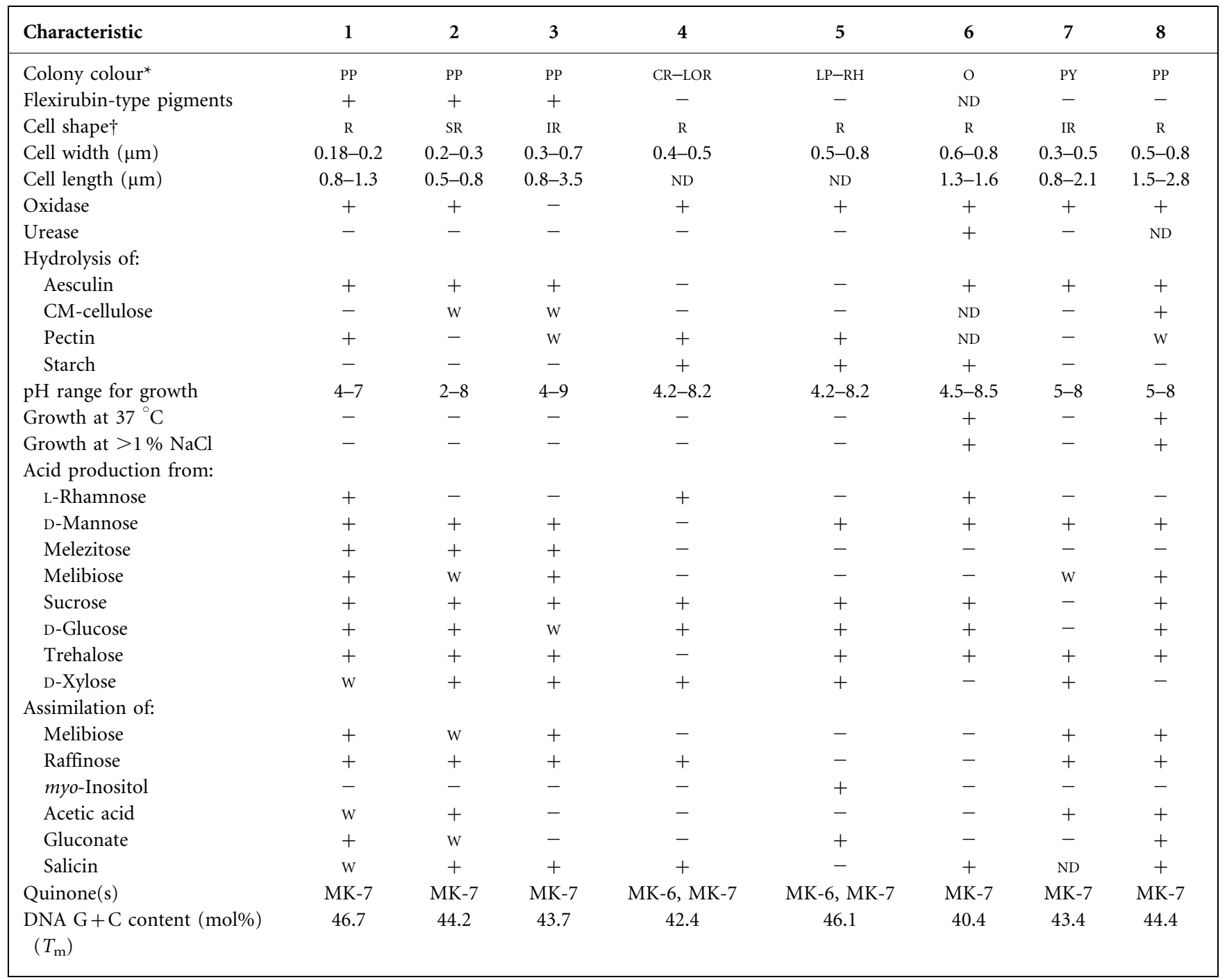

${ }^{*} \mathrm{CR}$, Cream; LOR, light orange-reddish; LP, light pink; O, orange; PP, pale pink; PY, pale yellow; RH, reddish.

$\dagger I R$, Irregular rods; R, rods; SR, short rods.

Chromosomal DNA was extracted according to the kit instructions (QIAamp DNA mini kit; Qiagen). The 16S rRNA gene was amplified using universal primers $27 \mathrm{~F}$ and $1492 \mathrm{R}$ as described by Madhaiyan et al. (2009) and the partial gene sequence was determined by the fluorescent dye terminator method using an ABI Prism Big Dye terminator cycle sequencing ready reaction kit version 3.1; products were run on an ABI 3730XL capillary DNA sequencer (ABI Prism 310 Genetic Analyzer; Applied Biosystems). The resultant $16 \mathrm{~S}$ rRNA gene sequence was compared with representative organisms from the same and related genera from GenBank and was aligned by using CLUSTAL w (Thompson et al., 1994). Phylogenetic relationships were determined by the neighbour-joining method (Saitou \& Nei, 1987) with the program package MEGA 4.1 (Tamura et al., 2007). Bootstrap confidence values were obtained using 1000 resamplings. DNA-DNA hybridization was carried out following the filter hybridization method (Seldin \& Dubnau, 1985). The hybridization temperature was $65{ }^{\circ} \mathrm{C}$ and DNA-DNA relatedness was 
quantified by using a densitometer (Bio-Rad). Probe labelling was conducted by using the non-radioactive DIG-High prime system (Roche Diagnostics) and hybridized DNA was visualized using the DIG luminescent detection kit according to the manufacturer's instructions (Roche Diagnostics). Fatty acid methyl ester analysis was carried out for a culture grown on R2A agar (Difco) at $28{ }^{\circ} \mathrm{C}$ for $48 \mathrm{~h}$ using the Microbial Identification System (Microbial ID; MIDI Inc.), according to standard protocols (Sasser, 1990). The G $+\mathrm{C}$ content of genomic DNA was determined by HPLC analysis using a reversed-phase column (Supelcosil LC-18S; Supelco) of individual nucleosides as described by Mesbah et al. (1989).

The phylogenetic tree obtained using selected 16S rRNA gene sequences showed that the strains were related to members of the Sphingobacteriaceae, having high similarity to members of the genus Mucilaginibacter. The16S rRNA gene sequence of strain Gh- $48^{\mathrm{T}}$ had $97.5,96.9,94.3$ and $95.2 \%$ pairwise similarity, respectively, to those from $M$. kameinonensis $\mathrm{SCK}^{\mathrm{T}}, M$. oryzae $\mathrm{B}^{\mathrm{T}}, M$. gracilis $\mathrm{TPT} 18^{\mathrm{T}}$ and M. paludis TPT56 ${ }^{\mathrm{T}}$. Strain Gh-67 ${ }^{\mathrm{T}}$ grouped with Gh$48^{\mathrm{T}}$ with $98.2 \%$ similarity, while it showed lower pairwise similarity to $M$. oryzae $\mathrm{B}^{\mathrm{T}}(96.7 \%)$, M. kameinonensis $\operatorname{SCK}^{\mathrm{T}}(96.5 \%)$, M. gracilis $\mathrm{TPT} 18^{\mathrm{T}}(93.9 \%)$ and M. paludis TPT56 $^{\mathrm{T}}(94.7 \%)$ (Fig. 1). Since strain Gh-67 ${ }^{\mathrm{T}}$ showed relatively low $16 \mathrm{~S}$ rRNA gene sequence similarity $(<97 \%)$ to its closest relatives, DNA-DNA hybridization was carried out for strain Gh- $48^{\mathrm{T}}$ only. It showed a low level of DNA-DNA relatedness to strain Gh- $67^{\mathrm{T}}(18 \%)$ and to M. kameinonensis KCTC $22227^{\mathrm{T}}(11 \%)$. The DNA G +C contents of strains $\mathrm{Gh}-67^{\mathrm{T}}$ and $\mathrm{Gh}-48^{\mathrm{T}}$ were 46.7 and $44.2 \mathrm{~mol} \%$, respectively. The fatty acid profiles of strains Gh- $67^{\mathrm{T}}$ and Gh- $48^{\mathrm{T}}$ (summarized in Table 2) consisted mainly of $\mathrm{C}_{16: 0}$, iso- $\mathrm{C}_{15: 0}$, iso- $\mathrm{C}_{17: 0} 3-\mathrm{OH}$ and summed feature $3\left(\mathrm{C}_{16: 1} \omega 7 c\right.$ and/or iso- $\left.\mathrm{C}_{15: 0} 2-\mathrm{OH}\right)$, which are normal components of other members of Mucilaginibacter (Pankratov et al., 2007; Urai et al., 2008). Based on the data presented, on the recommendation of Wayne et al. (1987) and on the suggestion that a low degree of 16S rRNA gene sequence similarity $(<97 \%)$ is sufficient for differentiating at the species level (Stackebrandt \& Goebel, 1994), strains Gh- $67^{\mathrm{T}}$ and Gh- $-48^{\mathrm{T}}$ represent novel species of the genus Mucilaginibacter, for which we propose the names Mucilaginibacter gossypii sp. nov. and Mucilaginibacter gossypiicola sp. nov., respectively.

\section{Description of Mucilaginibacter gossypii sp. nov.}

Mucilaginibacter gossypii (gos.sy'pi.i. N.L. gen. n. gossypii of Gossypium, the generic name of cotton, referring to the isolation of the type strain from the cotton rhizosphere).

Gram-negative, aerobic, non-endospore-forming, nonmotile, irregular rods, $0.18-0.20 \mu \mathrm{m}$ wide and 0.80 $1.25 \mu \mathrm{m}$ long (Supplementary Fig. S1). Growth occurs on AMS agar, R2A agar and NA, but not on TSA or MacConkey agar. Colonies are pale-pink, mucoid, convex and round with entire margins on R2A agar and AMS agar. Growth occurs at $20-30{ }^{\circ} \mathrm{C}$ with an optimum at $28{ }^{\circ} \mathrm{C}$. The $\mathrm{pH}$ range for growth is $\mathrm{pH} 4-7$, with optimum growth at pH 6-7. The pale-pink pigment is water-insoluble and has absorption maxima at 208, 263 and $478 \mathrm{~nm}$ in methanol. Growth occurs in the presence of $0.5 \%(\mathrm{w} / \mathrm{v}) \mathrm{NaCl}$, but not in the presence of $1 \%(\mathrm{w} / \mathrm{v}) \mathrm{NaCl}$ or higher. Flexirubin-type pigments are present. Tests for catalase, oxidase and pectinase are positive but urease and cellulase activities are absent. Proteolytic and lipolytic activities are present. Positive for hydrolysis of aesculin and pectin but negative for hydrolysis of gelatin, CM-cellulose and starch. Nitrate reduction is positive but negative for indole production. Methanol, dichloromethane, succinate and ethanol are utilized as sole carbon sources but trimethylamine, methylamine, diethanolamine, formaldehyde, acetate, formate, dimethylamine and methane are not. Ammonium chloride, potassium nitrate, sodium nitrate, L-alanine, L-glutamine, glycine, potassium thiocyanate, triethylamine and diethylamine are utilized as nitrogen sources but ACC, ammonium sulfate, L-glutamate, Laspartic acid, L-tryptophan, urea, methylamine, potassium cyanate and diphenylamine are not. The type strain is highly resistant (up to $500 \mu \mathrm{g} \mathrm{ml}^{-1}$ ) to spectinomycin, carbenicillin, gentamicin, kanamycin, nalidixic acid, bacitracin, cefotaxime, chloramphenicol, erythromycin, penicillin G, cephalosporin and trimethoprim, but sensitive to $\left(\mu \mathrm{g} \mathrm{ml}^{-1}\right.$ ) tetracycline (500), ampicillin (500), doxycycline (50), polymyxin B (300), rifampicin (100), novobiocin (500) and vancomycin (500). Positive for utilization of $\alpha$ cyclodextrin, dextrin, glycogen, $N$-acetyl-D-galactosamine, $\mathrm{N}$-acetyl-D-glucosamine, adonitol, D-arabitol, cellobiose, i-erythritol, D-fructose, L-fucose, D-galactose, gentiobiose, $\alpha$-D-glucose, lactose, lactulose, maltose, D-mannitol, Dmannose, melibiose, methyl $\beta$-D-glucoside, D-psicose, raffinose, L-rhamnose, D-sorbitol, sucrose, trehalose, tura-

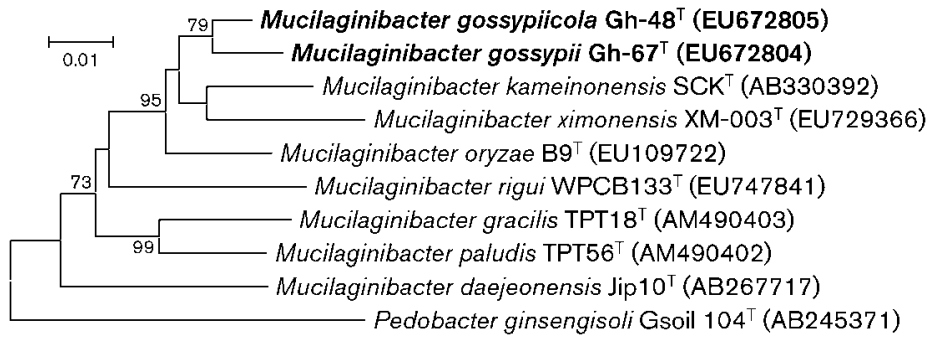

Fig. 1. Phylogenetic tree based on $16 \mathrm{~S}$ rRNA gene sequence comparison showing the positions of strains $\mathrm{Gh}-67^{\top}$ and $\mathrm{Gh}-48^{\top}$ and related members of the genus Mucilaginibacter. Numbers at nodes indicate percentages of occurrence in 1000 bootstrapped trees; values below $70 \%$ are not shown. Bar, 0.01 substitutions per site. 
Table 2. Cellular fatty acid compositions (\%) of Mucilaginibacter strains

Strains: 1, M. gossypii sp. nov. Gh-67 ${ }^{\mathrm{T}}$; 2, M. gossypiicola sp. nov. Gh- $48^{\mathrm{T}}$; 3, M. kameinonensis KCTC $22227^{\mathrm{T}}$; 4, M. gracilis KACC $13451^{\mathrm{T}}$; 5 , M. paludis KACC $13450^{\mathrm{T}} ; 6$, M. daejeonensis Jip $10^{\mathrm{T}}$; 7, M. ximonensis XM- $003^{\mathrm{T}}$; 8 , M. oryzae $\mathrm{B} 9^{\mathrm{T}}$. Data in columns $1-5$ were obtained in this study; data in columns 6-8 were taken from An et al. (2009); Luo et al. (2009) and Jeon et al. (2009). Values are percentages of total fatty acids. Fatty acids representing less than $0.1 \%$ in all strains were omitted. ECL, Equivalent chain-length; -, not detected/not reported.

\begin{tabular}{|c|c|c|c|c|c|c|c|c|}
\hline Fatty acid & 1 & 2 & 3 & 4 & 5 & 6 & 7 & 8 \\
\hline \multicolumn{9}{|l|}{ Saturated } \\
\hline $\mathrm{C}_{14: 0}$ & 1.2 & 1.7 & 1.4 & 1.2 & 1.3 & - & 1.3 & 1.7 \\
\hline$C_{16: 0}$ & 15.0 & 17.0 & 14.8 & 1.4 & 2.5 & 9.3 & 6.8 & 8.5 \\
\hline $\mathrm{C}_{17: 0}$ & 0.2 & 0.3 & 0.7 & 0.3 & - & - & - & - \\
\hline $\mathrm{C}_{18: 0}$ & 1.6 & - & - & - & - & 1.7 & 1.4 & - \\
\hline iso- $\mathrm{C}_{11: 0} 3-\mathrm{OH}$ & 0.3 & - & - & - & - & - & - & - \\
\hline $\mathrm{C}_{14: 0} 2-\mathrm{OH}$ & 0.3 & 0.6 & 0.5 & 0.4 & 0.2 & - & - & 0.6 \\
\hline iso- $\mathrm{C}_{14: 0} 3-\mathrm{OH}$ & - & - & - & - & - & - & - & 0.2 \\
\hline iso- $\mathrm{C}_{15: 0} 3-\mathrm{OH}$ & 1.9 & 4.5 & 8.7 & 3.2 & 1.5 & 2.2 & 1.9 & 2.2 \\
\hline $\mathrm{C}_{15: 0} 2-\mathrm{OH}$ & - & 0.6 & 0.4 & 0.2 & 0.2 & - & - & 0.3 \\
\hline iso- $\mathrm{C}_{16: 0} 3-\mathrm{OH}$ & 0.3 & 0.5 & 0.6 & 0.4 & 0.2 & - & - & 0.2 \\
\hline iso- $\mathrm{C}_{11: 0}$ & 0.2 & - & - & - & - & - & - & 0.1 \\
\hline iso- $\mathrm{C}_{13: 0}$ & 0.2 & - & 0.2 & 0.1 & 0.2 & - & - & - \\
\hline iso- $\mathrm{C}_{15: 0}$ & 25.8 & 20.2 & 19.3 & 29.5 & 17.5 & 26.5 & 26.2 & 23.9 \\
\hline anteiso- $\mathrm{C}_{15: 0}$ & - & - & - & 6.8 & 15.2 & 1.8 & - & 0.2 \\
\hline iso- $\mathrm{C}_{16: 0}$ & - & - & - & - & 1.4 & - & - & - \\
\hline iso- $\mathrm{C}_{17: 0}$ & 0.8 & - & 0.3 & 0.21 & - & - & 2.0 & 0.3 \\
\hline anteiso- $C_{17: 0}$ & - & 0.5 & - & - & 3.8 & - & - & - \\
\hline \multicolumn{9}{|l|}{ Unsaturated } \\
\hline $\mathrm{C}_{15: 1} \omega 6 \mathrm{c}$ & 0.7 & 0.6 & 0.5 & 1.3 & 1.2 & - & - & 0.4 \\
\hline $\mathrm{C}_{16: 1} \omega 5 c$ & 2.8 & 1.3 & 2.1 & 2.7 & 6.5 & 5.9 & 3.1 & 1.4 \\
\hline $\mathrm{C}_{17: 1} \omega 5 c$ & 1.5 & - & - & - & - & - & - & - \\
\hline 3 & 33.0 & 39.6 & 42.6 & 31.6 & 34.8 & 39.1 & 26.7 & 43.7 \\
\hline 4 & 0.5 & 0.6 & - & - & 0.1 & - & - & - \\
\hline \multicolumn{9}{|l|}{ Unknowns } \\
\hline ECL 13.565 & - & - & - & - & - & - & - & 0.7 \\
\hline ECL 16.582 & - & - & - & - & - & - & - & 0.3 \\
\hline
\end{tabular}

${ }^{\star}$ Summed features are groups of two or three fatty acids that cannot be separated using the MIDI system. Summed feature 2 contains unknown ECL 10.928 and/or $\mathrm{C}_{12: 0}$ aldehyde?; summed feature 3 contains $\mathrm{C}_{16: 1} \omega 7 \mathrm{c}$ and/or iso- $\mathrm{C}_{15: 0} 2-\mathrm{OH}$; summed feature 4 contains iso- $\mathrm{C}_{17: 1} \mathrm{I}$ and/or anteiso$\mathrm{C}_{17: 1} \mathrm{~B}$.

nose, xylitol, succinic acid monomethyl ester, acetic acid, cis-aconitic acid, D-gluconic acid, D-glucosaminic acid, Dglucuronic acid, $\alpha$-hydroxybutyric acid, $p$-hydroxyphenylacetic acid, itaconic acid, $\alpha$-ketobutyric acid, $\alpha$-ketoglutaric acid, DL-lactic acid, succinic acid, bromosuccinic acid, succinamic acid, L-alaninamide, D- and L-alanine, L-alanyl glycine, L-aspartic acid, L-glutamic acid, glycyl L-aspartic acid, glycyl L-glutamic acid, L-histidine, hydroxy-L-proline, L-ornithine, L-proline, L-serine, L-threonine, DL-carnitine, $\gamma$-aminobutyric acid, 2,3-butanediol, glycerol and DL- $\alpha$ glycerol phosphate. Other organic substrates included in the Biolog GN2 MicroPlate are not oxidized. The 
predominant respiratory quinone is MK-7. The main fatty acids are iso- $\mathrm{C}_{15: 0}, \mathrm{C}_{16: 0}$ and summed feature $3\left(\mathrm{C}_{16: 1} \omega 7 \mathrm{c}\right.$ and/or iso- $\mathrm{C}_{15: 0}$ 2-OH).

The type strain, Gh- $67^{\mathrm{T}}\left(=\mathrm{NCIMB} 14470^{\mathrm{T}}=\mathrm{KCTC}\right.$ $\left.22380^{\mathrm{T}}\right)$, was isolated from rhizosphere soil of cotton (Gossypium hirsutum L. 'MCU-12'), the sample being collected at the flowering stage from an experimental field at the Cotton Breeding Station, TNAU, India. The DNA $\mathrm{G}+\mathrm{C}$ content of the type strain is $46.7 \mathrm{~mol} \%$.

\section{Description of Mucilaginibacter gossypiicola sp. nov.}

Mucilaginibacter gossypiicola (gos.sy.pi.i.co'la. N.L. n. Gossypium a scientific botanical genus name; L. suff. -cola inhabitant, dweller; N.L. n. gossypiicola Gossypium-dweller, referring to the isolation of the type strain from the cotton rhizosphere).

Gram-negative, aerobic, non-endospore-forming, nonmotile, irregular rods, $0.2-0.3 \mu \mathrm{m}$ wide and $0.5-0.8 \mu \mathrm{m}$ long (Supplementary Fig. S1). Growth occurs on AMS agar, R2A agar and NA, but not on TSA agar or MacConkey agar. Colonies are pale-pink, mucoid, convex and round with entire margins on R2A agar and AMS agar. Growth occurs at $20-30{ }^{\circ} \mathrm{C}$ with an optimum at $28{ }^{\circ} \mathrm{C}$. The $\mathrm{pH}$ range for growth is $\mathrm{pH} 2-8$, with optimum growth at $\mathrm{pH}$ 6-7. The pale-pink pigment is water-insoluble and has absorption maxima at 213,262, 329, 346 and $479 \mathrm{~nm}$ in methanol. Growth occurs in the absence of $\mathrm{NaCl}$ and in the presence of $0.5 \%(\mathrm{w} / \mathrm{v}) \mathrm{NaCl}$, but not in the presence of $1 \%(\mathrm{w} / \mathrm{v}) \mathrm{NaCl}$ or higher. Flexirubin-type pigments are present. Tests for catalase, oxidase and cellulase are positive but pectinase and urease activities are absent. Proteolytic and lipolytic activities are present. Positive for hydrolysis of aesculin and CM-cellulose but negative for hydrolysis of pectin, gelatin and starch. Nitrate reduction is positive but negative for indole production. Methanol, dichloromethane, succinate and ethanol are utilized as sole carbon sources but trimethylamine, methylamine, diethanolamine, formaldehyde, acetate, formate, dimethylamine and methane are not. Ammonium chloride, potassium nitrate, ACC, L-alanine, L-glutamine, glycine, potassium thiocyanate, triethylamine and diethylamine are utilized as nitrogen sources but sodium nitrate, ammonium sulfate, L-glutamate, L-tryptophan, urea, methylamine, potassium cyanate and diphenylamine are not. The type strain is highly resistant (up to $500 \mu \mathrm{g} \mathrm{ml}^{-1}$ ) to spectinomycin, ampicillin, carbenicillin, gentamicin, kanamycin, nalidixic acid, bacitracin, cefotaxime, chloramphenicol, erythromycin, penicillin $G$, polymyxin $B$, novobiocin, vancomycin and trimethoprim, but sensitive to $\left(\mu \mathrm{g} \mathrm{ml}^{-1}\right)$ tetracycline (300), doxycycline (300), rifampicin (25) and cephalosporin (500). Positive for utilization of $\alpha$-cyclodextrin, dextrin, glycogen, $\mathrm{N}$-acetyl-D-galactosamine, $\mathrm{N}$-acetyl-D-glucosamine, adonitol, D-arabitol, cellobiose, i-erythritol, L-fucose, D-galactose, gentiobiose, $\alpha$-D-glucose, lactose, lactulose, maltose, D-mannitol, D-mannose, melibiose, methyl
$\beta$-D-glucoside, D-psicose, raffinose, D-sorbitol, sucrose, trehalose, turanose, xylitol, succinic acid monomethyl ester, acetic acid, cis-aconitic acid, D-gluconic acid, Dglucosaminic acid, D-glucuronic acid, $\alpha$-hydroxybutyric acid, $p$-hydroxyphenylacetic acid, itaconic acid, $\alpha$-ketobutyric acid, $\alpha$-ketoglutaric acid, DL-lactic acid, succinic acid, bromosuccinic acid, succinamic acid, L-alaninamide, Dand L-alanine, L-alanyl glycine, L-aspartic acid, L-glutamic acid, glycyl L-aspartic acid, glycyl L-glutamic acid, Lhistidine, hydroxy-L-proline, L-ornithine, L-proline, Lserine, L-threonine, DL-carnitine, $\gamma$-aminobutyric acid, 2,3-butanediol, glycerol and DL- $\alpha$-glycerol phosphate. Other organic substrates included in the Biolog GN2 MicroPlate are not oxidized. The predominant respiratory quinone is MK-7. The main fatty acids are iso- $\mathrm{C}_{15: 0}, \mathrm{C}_{16: 0}$ and summed feature $3\left(\mathrm{C}_{16: 1} \omega 7 c\right.$ and/or iso- $\left.\mathrm{C}_{15: 0} 2-\mathrm{OH}\right)$.

The type strain, Gh- $48^{\mathrm{T}} \quad\left(=\mathrm{NCIMB} 14471^{\mathrm{T}}=\mathrm{KCTC}\right.$ $\left.22379^{\mathrm{T}}\right)$, was isolated from rhizosphere soil of cotton $(G$. hirsutum L. 'MCU-12'), the sample being collected at the flowering stage from an experimental field at the Cotton Breeding Station, TNAU, Coimbatore, Tamilnadu, India. The DNA G + C content of the type strain is $44.2 \mathrm{~mol} \%$.

\section{Acknowledgements}

We wish to thank Peter N. Green, NCIMB, Aberdeen, UK, for his valuable advice. We also thank Dr Jean P. Euzéby for his valuable advice on nomenclature. This work was supported financially by the Indian Council of Agricultural Research (ICAR), New Delhi, India, and partially supported by grant from the KRIBB Research Initiative Program, Daejeon, Republic of Korea.

\section{References}

An, D.-S., Yin, C.-R., Lee, S.-T. \& Cho, C.-H. (2009). Mucilaginibacter daejeonensis sp. nov., isolated from dried rice straw. Int J Syst Evol Microbiol 59, 1122-1125.

Atlas, R. M. (1993). Handbook of Microbiological Media, pp. 196-843. Edited by L. C. Parks. Boca Raton, FL: CRC Press.

Baik, K. S., Park, S. C., Kim, E. M., Lim, C. H. \& Seong, C. N. (2010). Mucilaginibacter rigui sp. nov., isolated from wetland freshwater, and emended description of the genus Mucilaginibacter. Int J Syst Evol Microbiol 60, 134-139.

Blaha, D., Prigent-Combaret, C., Sajjad Mirza, M. \& Moënne-Loccoz, Y. (2006). Phylogeny of the 1-aminocyclopropane-1-carboxylic acid deaminase-encoding gene acdS in phytobeneficial and pathogenic Proteobacteria and relation with strain biogeography. FEMS Microbiol Ecol 56, 455-470.

Bozzola, J. J. \& Russell, L. D. (1998). Electron Microscopy, 2nd edn. Sudbury, MA: Jones \& Bartlett.

Chanprame, S., Todd, J. J. \& Widholm, J. M. (1996). Prevention of pink-pigmented methylotrophic bacteria (Methylobacterium mesophilicum) contamination of plant tissue cultures. Plant Cell Rep 16, 222225.

Egamberdieva, D., Kamilova, F., Validov, S., Gafurova, L., Kucharova, Z. \& Lugtenberg, B. (2008). High incidence of plant growth-stimulating bacteria associated with the rhizosphere of wheat grown on salinated soil in Uzbekistan. Environ Microbiol 10, $1-9$. 
Fautz, E. \& Reichenbach, H. (1980). A simple test for flexirubin-type pigments. FEMS Microbiol Lett 8, 87-91.

Floyd, M. M., Tang, J., Kane, M. \& Emerson, D. (2005). Captured diversity in a culture collection: case study of the geographic and habitat distribution of environmental isolates held at the American Type Culture Collection. Appl Environ Microbiol 71, 2813-2823.

Gerhardt, P. R., Murray, R. G. E., Wood, W. A. \& Krieg, N. R. (editors) (1994). Methods for General and Molecular Bacteriology. Washington, DC: American Society for Microbiology.

Ghosh, S., Penterman, J. N., Little, R. D., Chavez, R. \& Glick, B. R. (2003). Three newly isolated plant growth-promoting bacilli facilitate the seedling growth of canola, Brassica campestris. Plant Physiol Biochem 41, 277-281.

Glick, B. R., Jacobson, C. B., Schwarze, M. M. K. \& Pasternak, J. J. (1994). 1-Aminocyclopropane-1-carboxylic acid deaminase mutants of the plant growth promoting rhizobacterium Pseudomonas putida GR12-2 do not stimulate canola root elongation. Can J Microbiol 40, 911-915.

Glick, B. R., Patten, C. L., Holguin, G. \& Penrose, D. M. (1999). Biochemical and Genetic Mechanisms Used by Plant Growth Promoting Bacteria. London: Imperial College Press.

Green, P. N. \& Bousfield, I. J. (1982). A taxonomic study of some Gram-negative facultatively methylotrophic bacteria. J Gen Microbiol 128, 623-638.

Jeon, Y., Lee, S.-S., Chung, B.-S., Kim, J.-M., Bae, J.-W., Park, S.-K. \& Jeon, C. O. (2009). Mucilaginibacter oryzae sp. nov., isolated from soil of a rice paddy. Int J Syst Evol Microbiol 59, 1451-1454.

Kouker, G. \& Jaeger, K.-E. (1987). Specific and sensitive plate assay for bacterial lipase. Appl Environ Microbiol 53, 211-213.

Kroppenstedt, R. M. (1982). Separation of bacterial menaquinones by HPLC using reverse phase (RP18) and a silver loaded ion exchanger as stationery phases. J Liq Chromatogr 5, 2359-2367.

Li, J., Ovakim, D. H., Charles, T. C. \& Glick, B. R. (2000). An ACC deaminase minus mutant of Enterobacter cloacae UW4 no longer promotes root elongation. Curr Microbiol 41, 101-105.

Luo, X., Zhang, L., Dai, J., Liu, M., Zhang, K., An, H. \& Fang, C. (2009). Mucilaginibacter ximonensis sp. nov., isolated from Tibetan soil. Int J Syst Evol Microbiol 59, 1447-1450.

Madhaiyan, M., Poonguzhali, S., Ryu, J.-H. \& Sa, T.-M. (2006). Regulation of ethylene levels in canola (Brassica campestris) by 1-aminocyclopropane-1-carboxylate deaminase-containing Methylobacterium fujisawaense. Planta 224, 268-278.

Madhaiyan, M., Kim, B.-Y., Poonguzhali, S., Kwon, S.-W., Song, M.-H., Ryu, J.-H., Go, S.-J., Koo, B.-S. \& Sa, T.-M. (2007a). Methylobacterium oryzae sp. nov., an aerobic, pink-pigmented, facultatively methylotrophic, 1-aminocyclopropane-1-carboxylate deaminase-producing bacterium isolated from rice. Int J Syst Evol Microbiol 57, 326-331.

Madhaiyan, M., Poonguzhali, S. \& Sa, T.-M. (2007b). Metal tolerating methylotrophic bacteria reduces nickel and cadmium toxicity and promotes plant growth of tomato (Lycopersicon esculentum L.). Chemosphere 69, 220-228.

Madhaiyan, M., Poonguzhali, S., Kwon, S.-W. \& Sa, T.-M. (2009). Methylobacterium phyllosphaerae sp. nov., a pink-pigmented, facultative methylotroph from rice. Int J Syst Evol Microbiol 59, 22-27.

Mesbah, M., Premachandran, U. \& Whitman, W. B. (1989). Precise measurement of the $\mathrm{G}+\mathrm{C}$ content of deoxyribonucleic acid by highperformance liquid chromatography. Int J Syst Bacteriol 39, 159-167.
Pankratov, T. A., Tindall, B. J., Liesack, W. \& Dedysh, S. N. (2007). Mucilaginibacter paludis gen. nov., sp. nov. and Mucilaginibacter gracilis sp. nov., pectin-, xylan- and laminarin-degrading members of the family Sphingobacteriaceae from acidic Sphagnum peat bog. Int J Syst Evol Microbiol 57, 2349-2354.

Penrose, D. M. \& Glick, B. R. (2003). Methods for isolating and characterizing ACC deaminase-containing plant growth-promoting rhizobacteria. Physiol Plant 118, 10-15.

Poonguzhali, S., Madhaiyan, M. \& Sa, T. (2006). Cultivationdependent characterization of rhizobacterial communities from field grown Chinese cabbage Brassica campestris ssp pekinensis and screening of traits for potential plant growth promotion. Plant Soil 286, 167-180.

Saitou, N. \& Nei, M. (1987). The neighbor-joining method: a new method for reconstructing phylogenetic trees. Mol Biol Evol 4, 406425.

Sasser, M. (1990). Identification of bacteria through fatty acid analysis. In Methods in Phytobacteriology, pp. 199-204. Edited by Z. Klement, K. Rudolph \& D. C. Sands. Budapest: Akademiai Kiado.

Seldin, L. \& Dubnau, D. (1985). Deoxyribonucleic acid homology among Bacillus polymyxa, Bacillus macerans, Bacillus azotofixans, and other nitrogen-fixing Bacillus strains. Int J Syst Bacteriol 35, 151-154.

Stackebrandt, E. \& Goebel, B. M. (1994). Taxonomic note: a place for DNA-DNA reassociation and 16S rRNA sequence analysis in the present species definition in bacteriology. Int J Syst Bacteriol 44, 846849.

Steyn, P. L., Segers, P., Vancanneyt, M., Sandra, P., Kersters, K. \& Joubert, J. J. (1998). Classification of heparinolytic bacteria into a new genus, Pedobacter, comprising four species: Pedobacter heparinus comb. nov., Pedobacter piscium comb. nov., Pedobacter africanus sp. nov. and Pedobacter saltans sp. nov. Proposal of the family Sphingobacteriaceae. Int J Syst Bacteriol 48, 165-177.

Tamura, K., Dudley, J., Nei, M. \& Kumar, S. (2007). MEGA4: molecular evolutionary genetics analysis (MEGA) software version 4.0. Mol Biol Evol 24, 1596-1599.

Ten, L. N., Im, W.-T., Kim, M.-K., Kang, M.-S. \& Lee, S.-T. (2004). Development of a plate technique for screening of polysaccharide degrading microorganisms by using a mixture of insoluble chromogenic substrates. J Microbiol Methods 56, 375-382.

Thompson, J. D., Higgins, D. G. \& Gibson, T. J. (1994). CLUSTAL W: improving the sensitivity of progressive multiple sequence alignment through sequence weighting, position-specific gap penalties and weight matrix choice. Nucleic Acids Res 22, 4673-4680.

Urai, M., Aizawa, T., Nakagawa, Y., Nakajima, M. \& Sunairi, M. (2008). Mucilaginibacter kameinonensis sp. nov., isolated from garden soil. Int J Syst Evol Microbiol 58, 2046-2050.

Vessey, J. K. (2003). Plant growth promoting rhizobacteria as biofertilizers. Plant Soil 255, 571-586.

Wayne, L. G., Brenner, D. J., Colwell, R. R., Grimont, P. A. D., Kandler, O., Krichevsky, M. I., Moore, L. H., Moore, W. E. C., Murray, R. G. E. \& other authors (1987). International Committee on Systematic Bacteriology. Report of the ad hoc committee on reconciliation of approaches to bacterial systematics. Int J Syst Bacteriol 37, 463-464.

Whipps, J. M. (2001). Microbial interactions and biocontrol in the rhizosphere. J Exp Bot 52, 487-511.

Whittenbury, R., Davies, S. L. \& Wilkinson, J. F. (1970). Enrichment, isolation and some properties of methane-utilizing bacteria. J Gen Microbiol 61, 205-218. 